\title{
Fine needle aspiration cytology of palpable supraclavicular lymph nodes.
}

\author{
Adhikari RC ${ }^{1}$, Jha $\mathrm{A}^{1}$, Sayami G ${ }^{1}$, Shrestha $\mathrm{S}^{2}$, Sharma $\mathrm{SK}^{2}$ \\ ${ }^{1}$ Department of Pathology, Tribhuvan University Teaching Hospital, Kathmandu, Nepal \\ ${ }^{2}$ Om Hospital and Research Centre, Chabahil, Kathmandu, Nepal
}

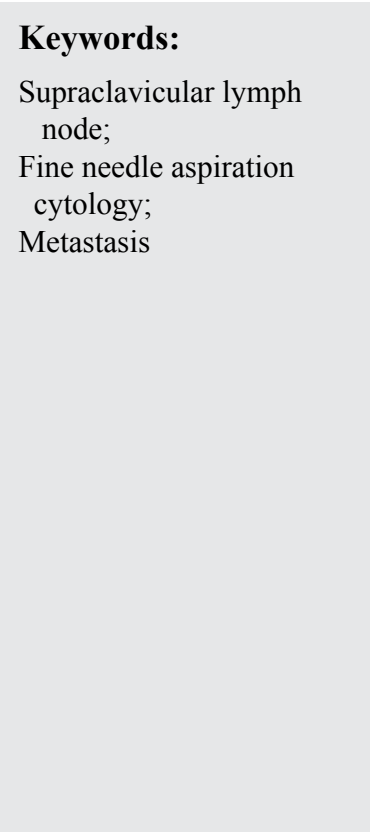

\begin{abstract}
Background: Fine needle aspiration cytology as a first line of investigation has assumed importance in diagnosing a variety of disease process. The aim of this study was to assess the diagnostic value of fine needle aspiration cytology in the evaluation of palpable supraclavicular lymph nodes.

Materials and methods: This was a retrospective study of fine needle aspiration cytology of palpable supraclavicular lymph node done between January 1, 2007 and December 31, 2009. Fine needle aspiration cytology was performed on 149 patients (49 cases at Om Hospital \& Research Centre and 100 cases at Tribhuvan University Teaching Hospital).

Results: The right supraclavicular lymph node was enlarged in 55\% cases, while the left supraclavicular lymph node alone was palpable in $40.3 \%$ cases and in 7 of 149 (4.7\%) cases, bilateral supraclavicular lymph nodes were palpable. Cytological diagnoses were categorized as reactive $(8.7 \%)$, tuberculosis $(41.6 \%)$, lymphoma $(4.8 \%)$ and metastasis $(44.9 \%)$. Of a total of 74 cases of malignancy, $90.5 \%$ were non-lymphoid and 9.5\% were lymphoid (5 Non-Hodgkin lymphoma and 2 Hodgkin lymphoma). Of the 67 cases of metastatic disease, three major types of malignancy found in supraclavicular lymph nodes were Squamous cell carcinoma (28 cases), adenocarcinoma (21 cases) and others (small cell carcinoma, papillary thyroid carcinoma etc). Adenocarcinoma tended to metastasize to the left supraclavicular lymph node. Lung was the most common primary site (43.3\%), followed by stomach, ovary, breast and larynx. However, in $28.4 \%$ cases, no primary site was found.
\end{abstract}

Conclusion: The fine needle aspiration cytology can be used as a first line investigation in the evaluation of supraclavicular lymphadenopathy due to its low cost, simplicity and minimal invasiveness.

\section{INTRODUCTION}

Fine needle aspiration cytology (FNAC) as a first line of investigation has assumed importance in diagnosing a variety of disease processes. It is a rapid, simple, safe and cost effective procedure, which can be performed in an outpatient setting. Furthermore, the aspirated samples can

\section{Correspondence:}

Dr. Ram Chandra Adhikari, $M D$

Department of Pathology, Om Hospital \& Research Centre

Chabahil, Kathmandu, Nepal

E-mail: rcadhikari@hotmail.com be utilized for immunocytochemistry and flow cytometry.

Supraclavicular lymph nodes are also known as "sentinel nodes" because of their accessibility to be palpated and their affinity for metastases. In many instances, a sentinel lymph node is the first sign of an underlying malignancy in the thoracic cavity, abdominal cavity or pelvic region. ${ }^{1}$ A variety of benign and malignant conditions presenting as supraclavicular lymphadenopathy can be diagnosed by FNAC. The significance of FNAC in the evaluation of enlarged supraclavicular lymph nodes has been shown in a few studies. ${ }^{2-6}$ 
Our experience of the diagnostic utility of FNAC in the assessment of supraclavicular lymphadenopathy is presented with an emphasis on the diagnosis of nonneoplastic, benign and malignant neoplastic processes. This study further emphasizes the utility of FNAC as the first line investigation for the evaluation of palpable supraclavicular lymph nodes.

\section{MATERIALS AND METHODS}

This study was a retrospective review of FNAC of palpable supraclavicular lymph nodes between January 1, 2007 and December 31, 2009. Data was retrieved from the records of the Department of Pathology, Tribhuvan University Teaching Hospital, Maharajgunj and Om Hospital \& Research Centre, Chabahil, Kathmandu, Nepal. FNAC was performed on 149 cases of palpable supraclavicular lymph nodes. Aspirates were procured by using a 21 gauge needle attached to a $10 \mathrm{ml}$ syringe. One to two passes were performed and aspirated material was smeared onto glass slides. Air dried smears were made for Giemsa staining and 95\% alcohol fixed smears were made for the Papanicolaou stain. Cytological evaluation was performed. The cytological diagnosis from each case was based on cytomorphology and available clinical information. The results were categorized as reactive, tuberculosis, lymphoma or metastasis.

\section{RESULTS}

A total of 149 FNACs were studied and the ages of the patients ranged from 5 to 86 years with a male to female ratio of 1.4:1. The right supraclavicular lymph node was enlarged in 82 of $149(55 \%)$ of the cases, while the left supraclavicular lymph node was only palpable in 60 of $149(40.3 \%)$ cases. In 7 of 149 (4.7\%) cases, bilateral supraclavicular lymph nodes were palpable. The size of the lymph nodes varied from 0.5 to $6 \mathrm{~cm}$. The lymph nodes in tuberculosis were multiple, firm and matted; while the majority of lymph nodes having metastatic disease were firm and fixed. Table 1 summarizes the FNAC diagnoses of supraclavicular lymph nodes. Of the 149 cases, 67 (44.9\%) showed metastatic disease and 62 (41.6\%) showed necrotizing granulomatous inflammation, which is consistent with tuberculosis (fig. 1). Five of 62 $(8 \%)$ cases of granulomatous inflammation showed acid fast bacilli using the Ziehl-Neelsen stain. Right supraclavicular lymph nodes were more frequently involved by tuberculosis than left supraclavicular lymph nodes.

Of the 74 cases of malignancy, $67(90.5 \%)$ were nonlymphoid and $7(9.5 \%)$ were lymphoid. Three major types of malignancy were found in the supraclavicular lymph nodes in the metastatic disease. They were squamous cell carcinoma (28 cases), adenocarcinoma (21 cases) and
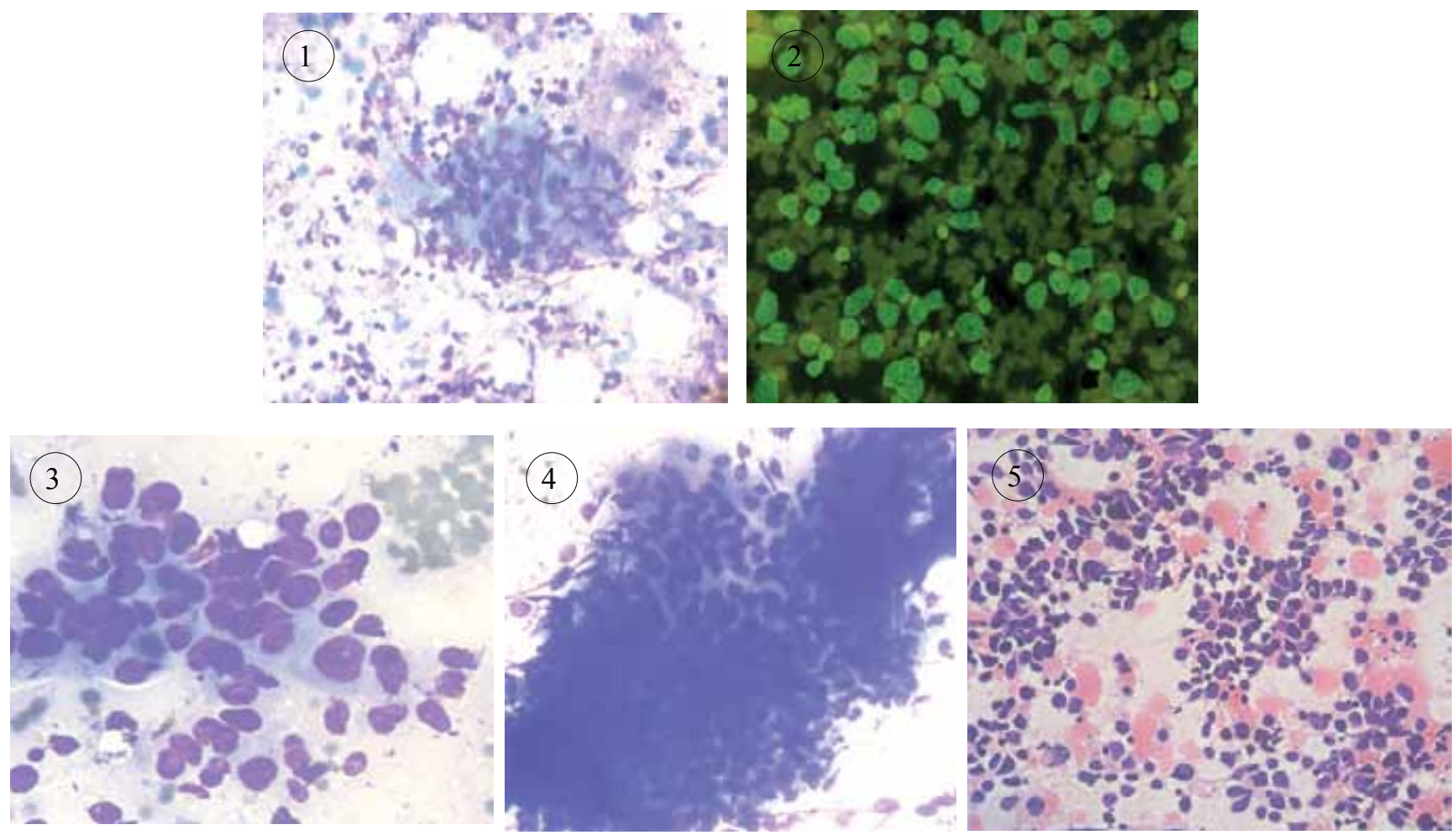

Figure 1: Tuberculous lymphadenitis, FNAC, Giemsa stain, X400. Aggregates of epithelioid cells seen.

Figure 2: Non-Hodgkin's lymphoma, FNAC, Giemsa stain, X400. Singly dispersed large atypical lymphoid cells with lymphoid globules on the background.

Figure 3: Metastatic adenocarcinoma, FNAC, Giemsa stain, X400.

Figure 4: Metastatic squamous cell carcinoma, FNAC, Giemsa stain, X400.

Figure 5: Metastatic small cell carcinoma, FNAC, H\&E stain, X400. 
others (small cell carcinoma, papillary thyroid carcinoma, neuroendocrine carcinoma, large cell carcinoma, mixed adenocarcinoma and small cell carcinoma and poorly differentiated carcinoma). Lymphoid neoplasm included 5 cases of Non-Hodgkin lymphoma (fig. 2) in males and 2 cases of Hodgkin lymphoma in females. Both Non-Hodgkin and Hodgkin lymphoma showed no site predilection between right and left supraclavicular lymph nodes.

Adenocarcinoma (fig. 3) from all sites except lung and breast tended to metastasize to the left supraclavicular lymph node. Lung adenocarcinoma showed no site predilection.

Table 1: FNAC diagnoses of Supraclavicular lymph nodes (SCLN)

\begin{tabular}{lcccc}
\hline \multicolumn{1}{c}{ FNAC Diagnosis } & $\begin{array}{c}\text { No. of } \\
\text { cases } \\
(\mathbf{\%})\end{array}$ & Male & Female & $\begin{array}{c}\text { Mean } \\
\text { age }\end{array}$ \\
\hline Metastasis & $67(44.9)$ & 35 & 32 & 59.0 \\
\hline $\begin{array}{l}\text { Tuberculosis } \\
\text { Reactive } \\
\text { lymphadenitis }\end{array}$ & $13(41.6)$ & 19 & 43 & 35.1 \\
\hline $\begin{array}{l}\text { Non-Hodgkin } \\
\text { lymphoma }\end{array}$ & $5(3.4)$ & 5 & 10 & 39.4 \\
\hline Hodgkin lymphoma & $2(1.4)$ & - & - & 71.8 \\
\hline Total & $149(100)$ & $\begin{array}{c}62 \\
(41.6 \%)\end{array}$ & $\begin{array}{c}87 \\
(58.4 \%)\end{array}$ & - \\
\hline
\end{tabular}

Breast carcinoma showed predilection towards the right supraclavicular lymph node. Squamous cell carcinomas (fig. 4) were distributed with $46.4 \%$ (13 cases) being in the left supraclavicular lymph node, $50 \%$ (14 cases) in the right supraclavicular lymph node and 3.6\% (1 case) in both supraclavicular lymph nodes. Squamous cell carcinoma of the lung had a tendency to metastasize to the right supraclavicular lymph node. Small cell carcinomas (fig. 5)

Table 3: Primary sites in case of SCLN metastasis

\begin{tabular}{lcccc}
\hline \multicolumn{1}{c}{ Primary site } & $\begin{array}{c}\text { No. of } \\
\text { cases }\end{array}$ & $\begin{array}{c}\text { Left } \\
\text { SCLN }\end{array}$ & $\begin{array}{c}\text { Right } \\
\text { SCLN }\end{array}$ & Both \\
\hline Lung & 29 & 10 & 17 & 2 \\
\hline Stomach & 3 & 3 & - & - \\
\hline Ovary & 3 & 2 & 1 & - \\
\hline Breast & 3 & 1 & 2 & - \\
\hline Larynx & 3 & 2 & 1 & - \\
\hline Cervix & 2 & 1 & 1 & - \\
\hline Duodenum & 1 & 1 & - & - \\
\hline Esophagus & 1 & - & 1 & - \\
\hline Pharynx & 1 & - & 1 & - \\
\hline Kidney & 1 & 1 & - & - \\
\hline Thyroid gland & 1 & - & 1 & - \\
\hline Unknown & 19 & 12 & 5 & 2 \\
\hline Total & $\mathbf{6 7}$ & $\mathbf{3 3}$ & $\mathbf{3 0}$ & $\mathbf{4}$ \\
\hline
\end{tabular}

Table 2: Incidence of Supraclavicular lymph node metastases in a total of 67 cases

\begin{tabular}{|c|c|c|c|c|c|}
\hline FNAC diagnosis & Primary site & Left & Right & Both & Total \\
\hline \multirow{7}{*}{ Adeno-carcinoma } & Unknown & 6 & 1 & 1 & 8 \\
\hline & Lung & 1 & 1 & 1 & 3 \\
\hline & Stomach & 3 & - & - & 3 \\
\hline & Ovary & 2 & 1 & - & 3 \\
\hline & Breast & 1 & 2 & - & 3 \\
\hline & Duodenum & 1 & - & - & 1 \\
\hline & Total & 14 & 5 & 2 & 21 \\
\hline \multirow{8}{*}{$\begin{array}{l}\text { Squamous cell } \\
\text { carcinoma }\end{array}$} & Unknown & 6 & 4 & 1 & 11 \\
\hline & Lung & 3 & 6 & - & 9 \\
\hline & Larynx & 2 & 1 & - & 3 \\
\hline & Cervix & 1 & 1 & - & 2 \\
\hline & Esophagus & - & 1 & - & 1 \\
\hline & Pharynx & - & 1 & - & 1 \\
\hline & Kidney & 1 & - & - & 1 \\
\hline & Total & 13 & 14 & 1 & 28 \\
\hline \multirow{7}{*}{ Other malignancies } & Small cell carcinoma (lung) & 4 & 5 & 1 & 10 \\
\hline & Poorly differentiated carcinoma (lung) & 1 & 2 & - & 3 \\
\hline & Large cell carcinoma (lung) & - & 2 & - & 2 \\
\hline & Neuroendocrine carcinoma (lung) & - & 1 & - & 1 \\
\hline & Mixed adenocarcinoma and small cell carcinoma (lung) & 1 & - & - & 1 \\
\hline & Thyroid gland (papillary carcinoma) & - & 1 & - & 1 \\
\hline & Total & 6 & 11 & 1 & 18 \\
\hline
\end{tabular}


do not show any predilection.

The details of the primary sites are summarized in Table 2 and 3. Lung was the most common primary site in 29 of $67(43.3 \%)$ cases, followed by stomach, ovary, breast and larynx. In 19 of $67(28.4 \%)$ cases, no primary site was found. Other primary sites were cervix, thyroid gland, kidney, pharynx, esophagus and duodenum. Reactive lymphadenitis was found in $13(8.7 \%)$ of the cases.

\section{DISCUSSION}

Supraclavicular lymph nodes are easily accessible to palpation and they are a common repository of metastatic malignancies. ${ }^{7}$ FNAC of supraclavicular lymph nodes is useful as a first line of investigation due to its simplicity and cost effectiveness as well as easy sample accessibility. Studies have indicated the value of FNAC in evaluating the palpable supraclavicular lymph nodes. ${ }^{2,4,5,8,9}$ Similar to those studies, this study shows that FNAC is useful in diagnosing infectious, reactive and neoplastic processes.

Tuberculous lymphadenitis was a cause of $41.6 \%$ of the supraclavicular lymphadenopathies. This is high compared to the studies of Gupta $\mathrm{N}$ et $\mathrm{al}^{6}(13.5 \%)$ and Nasuti JF et $\mathrm{al}^{5}$ $(2 \%)$. The high incidence may be due to the high prevalence of tuberculosis in Nepal. For unknown reasons, the right supraclavicular lymph nodes were more frequently involved than the left supraclavicular lymph nodes.

Lymphoid malignancy represents a minority of the tumors $(7-13 \%)^{5}$ in other studies as well as in our study $(9.5 \%)$. As was the case in previous reports ${ }^{5}$, lymphoid malignancy represented a minority of the tumors in the current study.

Adenocarcinomas metastasize to the supraclavicular lymph nodes from the primary tumor sites of the breast ${ }^{1}$, lung, ${ }^{11}$ prostate $^{12}$, stomach $^{13}$, pancreas ${ }^{14}$, esophagus ${ }^{4}$ and endometrium..$^{15}$ In addition to these primary sites, we also observed metastases from the ovary and duodenum. In some cases, a previous history of malignancy was known. Involvement of the supraclavicular lymph node in these malignancies is often associated with a poor prognosis. ${ }^{10}$

Squamous cell carcinomas usually metastasize to the supraclavicular lymph nodes from the cervix, ${ }^{16}$ mediastinum, ${ }^{17}$ esophagus ${ }^{18}$ and lung. ${ }^{4}$ In addition to this, we observed metastases from the larynx, pharynx and kidney. There were also cases of squamous cell carcinoma that had unknown primary sites.

Small cell carcinoma of the lung can metastasize to the supraclavicular lymph nodes and this results in an unfavorable prognosis. ${ }^{19} \mathrm{We}$ found all small cell carcinomas in supraclavicular lymph nodes to arise from the lungs.

We found that other lung carcinomas like large cell carcinoma, neuroendocrine carcinoma, mixed adenocarcinoma and small cell carcinoma and papillary carcinoma of thyroid gland have also metastasized to the supraclavicular lymph nodes.

Our data concurs with the observation that most adenocarcinomas metastasize to the left supraclavicular lymph node. In this study, squamous cell carcinomas show no predilection to the side that they metastasize to. In contrast, Carson $\mathrm{HJ}_{\text {et }} \mathrm{al}^{4}$, found that squamous cell carcinomas appeared to favor the right side. The cause for this remains unclear. Similar to squamous cell carcinoma, small cell carcinomas did not show a sidewise predilection in this study.

This study shows that metastatic tumors are more common in supraclavicular lymph nodes than lymphoid malignancy and adenocarcinomas show a greater tendency to metastasize to the supraclavicular lymph nodes. ${ }^{4,5,9}$

\section{CONCLUSION}

The FNAC can be used as a first line investigation in the evaluation of supraclavicular lymphadenopathy due to its low cost, simplicity and minimal invasiveness. In addition, it saves the patient from unnecessary biopsies.

\section{REFERENCES}

1. Moore KL. The thorax. In: Moore KL, editor. Clinically oriented anatomy, 2nd ed. Baltimore: Williams and Wilkins; 1985. pp 49-148.

2. Gupta RK, Naran S, Lallu S, Fauck R. The diagnostic value of fine needle aspiration cytology (FNAC) in the assessment of palpable supraclavicular lymph nodes: a study of 218 cases. Cytopathology 2003;14:201-7.

3. Handa U, Mohan H, Bal A. Role of fine needle aspiration cytology in evaluation of paediatric lymphadenopathy. Cytopathology 2003;14:66-9.

4. Carson HJ, Candel AG, Gattuso P, Castelli MJ. Fine-needle aspiration of supraclavicular lymph nodes. Diagn cytopathol 1996;14:216-20.

5. Nasuti JF, Mehrotra R, Gupta PK. Diagnostic value of fine-needle aspiration in supraclavicular lymphadenopathy: a study of 106 patients and review of literature. Diagn Cytopathol 2001;25:351-5.

6. Gupta N, Rajwanshi A, Srinivasan R, Nijhawan R. Pathology of supraclavicular lymphadenopathy in Chandigarth, north India: an audit of 200 cases diagnosed by needle aspiration. Cytopathology 2006;17:94-6.

7. Sriwatanawangsa V, Cardoso R, Chang P. Incidence of malignancy in peripheral lymph node biopsy. Am Surg 1985;51:587-90.

8. Cervin JR, Silverman JF, Loggie BW, Geisinger K. Vichow's node revisited: analysis with clinicopathologic correlation of 152 fineneedle aspiration biopsies of supraclavicular nodes. Arch Pathol Lab med 1995; 119:727-30.

9. McHenry CR, Cooney MW, Slusarczyk SJ, Khiyami A. Supraclavicular lymphadenopathy: the spectrum of pathology and evaluation of fine-needle aspiration biopsy. Am Surg 1999;65:742-6.

10. Kiricuta IC, Willner J, Kolbl O, Bohndorf W. The prognostic significance of the supraclavicular lymph node metastasis in breast cancer patients. Int J Radiat Oncol Biol Phys 1994;28:387-93. 
11. Sugama Y, Kitamura S. Ultrasonographic evaluation of neck and supraclavicular lymph nodes metastasized from lung cancer. Int Med 1992;31:160-4.

12. McMenamin PG, Anderson JD, Baker JJ. Prostatic carcinoma presenting with neck metastases. J Otolaryngol 1989;18:119-24.

13. Metayer P, Antonietti M, Oumrani M, Hemet J, Lemoine F, Basuyau $\mathrm{J}$. Metastases of a gastric adenocarcinoma presenting as colonic polyposis. Report of a case. Dis Colon Rectum 1991;34:622-3.

14. Khorsand J, Katz RL, Savaraj N. Malignant carcinoid of the pancreas: a cytologic ultrastructural and immunocytochemical study of a case diagnosed by fine-needle aspiration of a supraclavicular lymph node metastasis. Diagn Cytopathol 1987;3:222-7.
15. Foote RL, Schray MF, Wilson TO, Malkasian GDJr. Isolated peripheral lymphnode recurrence of endometrial carcinoma. Cancer 1988;61:2561-5.

16. Yao $\mathrm{ZH}, \mathrm{Wu}$ AR. Supraclavicular lymph node metastasis from carcinoma of the uterine cervix after radiotherapy - analysis of 219 patients. Chung - Hua Chung Liu Tsa Chih 1988;10:230-2.

17. Bharat M, Rybak LP, Dietrich J. Metastatic thymoma to the head and neck. Laryngoscope 1988;98:418-21.

18. Okuma T, Kaneko H, Yoshioka M, Torigoe Y, Miyauchi Y. Prognosis in esophageal carcinoma with cervical lymph node metastases. Surgery 1993;114:513-8.

19. Spiegelman D, Maurer LH, Ware JH et al. Prognostic factors in small cell carcinoma of the lung: an analysis of 1521 patients. J Clin Oncol 1989;7:344-54. 